\title{
Assessment and treatment of posttraumatic anger and aggression: A review
}

\author{
Casey T. Taft, PhD; ${ }^{1-2 *}$ Suzannah K. Creech, PhD; ${ }^{1,3}$ Lorig Kachadourian, $\mathbf{P h D}^{1-2}$ \\ ${ }^{1}$ National Center for PTSD, Department of Veterans Affairs (VA) Boston Healthcare System, Boston, MA; ${ }^{2}$ Boston Uni- \\ versity School of Medicine, Boston, MA; ${ }^{3}$ Providence VA Medical Center, Providence, RI; and Warren Alpert Medical \\ School of Brown University, Providence, RI
}

\begin{abstract}
The Department of Veterans Affairs (VA) and Department of Defense's (DOD) recently published and updated Department of Veterans Affairs/Department of Defense VA/ DOD Clinical Practice Guideline for Management of PostTraumatic Stress includes irritability, severe agitation, and anger as specific symptoms that frequently co-occur with PTSD. For the first time, the guideline includes nine specific recommendations for the assessment and treatment of PTSDrelated anger, irritability, and agitation. This article will review the literature on PTSD and its association with anger and aggression. We highlight explanatory models for these associations, factors that contribute to the occurrence of anger and aggression in PTSD, assessment of anger and aggression, and effective anger management interventions and strategies.
\end{abstract}

Key words: aggression, agitation, anger, assessment, irritability, PTSD, trauma, treatment, veterans, violence.

\section{INTRODUCTION}

In 2010, the Department of Veterans Affairs (VA) and the Department of Defense (DOD) published the $\underline{V A}$ / DOD Clinical Practice Guideline for Management of Post-Traumatic Stress [1]. This document is designed to assist practitioners working with patients experiencing traumatic stress disorders and acute stress reactions. Included in this guideline for the first time is the discussion of anger, irritability, and severe agitation (Table), since these symptoms represent a component of PTSD hyperarousal and are increasingly being viewed as a defining feature of patients' clinical presentations.

\section{METHODS}

We begin by reviewing literature on the associations between PTSD and both anger and aggression. The review that occurred for the update in the 2010 VA/DOD PTSD clinical practice guideline and additional relevant literature published since that guideline review is included. We then discuss theoretical models that have been proposed to explain these associations. Other factors that contribute to anger and aggression in PTSD are also discussed, including depression and alcohol use, as well as disruptions in core schemas related to trust, selfesteem, and power and control. The different assessments available for practitioners are then discussed, followed by

\footnotetext{
Abbreviations: $\mathrm{AX}=$ Anger Expression Index, CTS2 = Revised Conflict Tactics Scale, DOD = Department of Defense, PTSD = posttraumatic stress disorder, STAXI = StateTrait Anger Expression Inventory, TBI = traumatic brain injury, VA = Department of Veterans Affairs.

*Address all correspondence to Casey T. Taft, PhD; VA Boston Healthcare System (116B-4), 150 S. Huntington Ave, Boston, MA 02130; 857-364-6261. Email: casey.taft@va.gov http://dx.doi.org/10.1682/JRRD.2011.09.0156
} 
a discussion of interventions for managing anger and aggression and additional treatment considerations.

\section{RESULTS}

\section{PTSD and Anger}

Early definitions of anger focused on physiological experiences such as increased heart rate and skin conductance level [2], while later definitions focused on more subjective experiences. For example, Spielberger et al. defined anger as "an emotional state that consists of feelings that vary in intensity from mild irritation or annoyance to intense fury and rage" [3]. Although useful, such definitions exclude other aspects of the anger experience, including behaviors and cognitions [4]. More recent definitions consider the multifaceted nature of anger and include physiological (e.g., muscle tone, autonomic arousal), cognitive (e.g., attitudes, attributions, self-talk, imagery), affective (e.g., subjective experience of feelings), and behavioral (e.g., overt behavior and verbal forms of expression) components [5]. For example, Kassinove and Sukhodolsky define anger as "a negative, phenomenological (or internal) feeling state associated with specific cognitive and perceptual distortions and deficiencies (e.g., misappraisals; errors; and attributions of blame, injustice, preventability, and/or intentionality), subjective labeling, physiological changes, and action tendencies to engage in socially constructed and reinforced organized behavioral scripts” [6].

Anger is similar to, but distinct from, several related concepts. For example, although anger is associated with aggression, they are separate constructs. Aggression consists of certain behaviors that are intended to cause harm to another person [7] and can include such acts as verbal abuse, threats, or violence [8]. Although anger can be considered a prelude to aggression and individuals who become aggressive are more likely to be angry, not all who are angry will become aggressive [9]. Anger also can be distinguished from hostility. Hostility can be likened to a type of attitude that involves a negative evaluation of another person or thing [10]. As defined by Berkowitz, hostility is "a negative attitude toward one or more people that is reflected in a decidedly unfavorable judgment of the target” [11]. Hostility can be considered more cognitive in nature, and such cognitions may result in anger.
Table.

VA/DOD Clinical Practice Guideline for Management of PostTraumatic Stress: managing irritability, severe agitation, and anger.

\begin{tabular}{cl}
\hline Number & \multicolumn{1}{c}{ Guideline } \\
\hline 1 & $\begin{array}{l}\text { Assessment of anger symptoms, severity, and } \\
\text { dangerousness using standardized measures. }\end{array}$ \\
2 & $\begin{array}{l}\text { Explore causal factors and monitor changes. } \\
\text { Refer to specialty care for marital or family therapy, } \\
\text { anger management therapy, training in exercise } \\
\text { and relaxation techniques. }\end{array}$ \\
& $\begin{array}{l}\text { Promote participation in enjoyable activities- } \\
\text { especially with family/loved ones. }\end{array}$ \\
5 & $\begin{array}{l}\text { Promote sleep and relaxation. } \\
6\end{array}$ \\
7 & Avoid stimulants and other substances. \\
8 & Avoid benzodiazepines. \\
9 & Consider SSRIs/SNRIs.
\end{tabular}

SNRI = serotonin-norepinephrine reuptake inhibitor, SSRI = selective serotonin reuptake inhibitor.

As can be expected, a great deal of research has been conducted documenting the positive association between PTSD and anger [12-15]. Summarizing this literature empirically, Orth and Wieland conducted a meta-analysis and found that the mean effect size $(r)$ between PTSD and anger was 0.48 , indicating a large effect [16]. They also examined the association between PTSD and specific anger dimensions on the State-Trait Anger Expression Inventory (STAXI) [17], including “anger-in,” "anger-out," and "anger control.” Anger-in involves the inhibition and nondisclosure of anger, as well as a ruminative focus on one's anger. Anger-out involves the outward expression of anger (e.g., slamming doors, arguing, making sarcastic remarks). Anger control involves strategies used to control one's anger (e.g., being tolerant and understanding, controlling one's behavior). Findings showed effect sizes of $0.53,0.29$, and -0.44 for anger-in, anger-out, and anger control, respectively, all representing medium to large effect sizes. Importantly, as noted by the authors, the studies included in the meta-analysis varied in sample and methodological characteristics, thus strengthening the generalizability of the results. More recently, Olatunji et al. conducted a meta-analysis examining the association between anger and PTSD, as well as other anxiety disorders [18]. In addition to finding that a diagnosis of PTSD was associated with greater difficulties with anger, more so than any other anxiety disorder diagnosis, the association between PTSD and anger varied depending on the anger domain assessed, with anger-in, 
anger-out, and anger control differentiating PTSD from non-PTSD anxiety.

Orth and Wieland also examined possible moderators of the association between PTSD and anger [16]. One such moderator was the type of traumatic event that resulted in PTSD. Specifically, studies that used samples of individuals exposed to military traumas had stronger effect sizes compared with samples of individuals exposed to other types of traumatic events. Although this finding suggests that military war experiences have more of an effect on the relationship between anger and PTSD compared with other events, Orth and Wieland noted that it could also be that individuals selected for military service may differ from the general population in that they may be higher in trait anger and dispositional aggressiveness [16]. Thus, it may not be the event itself that causes the stronger association, but rather the pre-event selection, that could account for the larger effect size in samples with military war experience.

In addition to studies finding strong support for the relationship between anger and PTSD in military samples, studies have also shown that Veterans diagnosed with PTSD demonstrate higher levels of anger compared with Veterans without PTSD [12,19-23]. For example, Chemtob et al. conducted a study in which they compared 24 Vietnam war Veterans who had been diagnosed with PTSD to 23 non-PTSD Vietnam combat Veterans and 12 noncombat Vietnam-era Veterans with psychiatric diagnoses [12]. Results showed that PTSD-positive Veterans scored significantly higher on anger-related measures compared with the other two groups. Given the comparison groups used in this study, the findings could not be attributed to combat exposure or to psychiatric disorders since both the combat control group and the psychiatric group scored lower in anger than the PTSD group. These authors also found that the differences between the three groups in anger could not be accounted for by any differences in impulsivity because the groups did not differ on this variable. This study is important because it documented the association between anger and PTSD among military samples. However, this study focused exclusively on Vietnam-era Veterans, raising the question of whether similar associations would be found among Veterans of other eras. More recently, Jakupcak et al. examined Veterans from the Iraq and Afghanistan wars who screened positive for PTSD and compared them with those who demonstrated subthreshold levels of PTSD and those without PTSD on trait anger, hostility, and aggression [22]. Findings showed that the PTSD group reported greater anger and hostility than the subthreshold PTSD Veterans, who in turn scored higher than the non-PTSD group. This study thus extended the previous findings reported by Chemtob et al. [12] to Veterans of a more contemporary era and provided further support for the anger-PTSD association.

Considering that anger and irritability represent a symptom of PTSD, one important question is whether or not associations between PTSD and anger are inflated because of the presence of anger items on PTSD scales. In other words, documented associations may represent statistical artifacts given that anger items are present on both the PTSD and anger measure. We are aware of two studies that have directly addressed this question by removing anger-related items from the PTSD measure and examining whether associations were substantially reduced relative to associations involving the full PTSD measure (including anger items): one in a sample of Vietnam combat Veterans [24] and the other in a sample of female crime victims [25]. Both studies demonstrated that associations were virtually unchanged when the angerrelated items were removed from the PTSD measure.

The co-occurrence of anger and PTSD has important implications for PTSD treatment since anger may interfere with the effectiveness of PTSD treatments. For example, Forbes et al. examined the influence of anxiety, depression, anger, and alcohol use on symptom change among Vietnam Veterans in treatment for PTSD [24]. Veterans were assessed at pretreatment and again 9 months after treatment concluded. Results showed that anger had a negative effect on treatment; that is, those with lower anger fared better (i.e., had lower symptoms of PTSD) at the follow-up assessment than those with higher levels of anger. How might anger affect such outcomes? As noted by Forbes et al., there may be several ways, including the possibility that anger may negatively affect the therapeutic alliance or that individuals may be afraid to access fear-relevant memories because doing so may activate their anger and trigger attack behaviors [26]. That Veterans may be hesitant to experience anger is not surprising given that Veterans often report that anger is the problem that interferes most with functioning [27]. Importantly, in their recent study, Forbes et al. found that fear of anger (that is, the extent to which an individual is fearful of experiencing their own anger because of possible negative consequences), in addition to alcohol-related comorbidity, mediated the association between anger severity 
and PTSD treatment outcome [26]. Such findings provide further understanding of the effect that anger can have on the effectiveness of PTSD treatments and elucidates the specific anger-related factors involved, namely a fear of experiencing this emotion. Thus, as noted by Forbes et al., assessments for those seeking treatment for PTSD should focus not only on the severity of anger but also on the extent to which an individual fears experiencing such anger [26].

\section{PTSD and Aggression}

An association between symptoms of PTSD and both general and partner aggression has been consistently demonstrated in Veteran and civilian populations [22,2833]. In the nationally representative National Vietnam Veterans Readjustment Study [34], 13.5 percent of Veterans without PTSD were identified as partner-violent during the previous year, whereas 33 percent of Veterans with PTSD perpetrated violence [35]. Another study reported a negative association between combat exposure and intimate partner violence when examined together in a structural equation modeling analysis that included various other predictors, including PTSD symptoms [36]. Thus, combat exposure alone is a relatively weak correlate of aggression, and what appears to truly elevate risk for aggression is the development of PTSD and traumarelated psychopathology [35-38].

Evidence indicates that the three PTSD symptom clusters of re-experiencing, avoidance/numbing, and hyperarousal may differentially affect aggression. Increasingly, the hyperarousal cluster has been shown to be most strongly associated with aggression [30,39]. In an analysis of the effect of each of the symptom clusters on general physical aggression in 1,328 male Vietnam Veterans, Taft et al. showed a negative association between avoidance/numbing symptoms and aggression, and re-experiencing symptoms were only indirectly associated with aggression through a positive relationship with physiological reactivity and a negative relationship with alcohol problems [30]. In contrast, hyperarousal symptoms had a significant positive relationship with aggression.

\section{Explanatory Models}

We have recently argued that information processing deficits help explain why Veterans with PTSD are at higher risk for difficulties with anger and aggressive behavior when returning from a deployment [40]. Infor- mation processing models for aggression emphasize how an individual interprets or decodes social situations [41], and the literature indicates that men who engage in aggression display more irrational beliefs and cognitive biases when angry than nonviolent men [42]. Veterans with PTSD may be particularly likely to interpret ambiguous situations in an overly hostile or negative manner and are more likely to perceive an event as threatening when it is not truly so [43]. As Chemtob et al. [44-45] and Novaco and Chemtob [46] discuss, military personnel in the war zone need to be constantly alert to any potential threats in their environment and develop an acute sense of threat perception. They are trained to recognize minor changes in their environment that may represent potential threats (e.g., roadside bombs), and this heightened sense of threat is adaptive in the war zone in that it assists in navigating dangerous environments. However, if the military member develops PTSD, he or she may be more likely to misread social situations and mistakenly view others as having hostile or negative intentions and respond to such perceptions in an angry and/or aggressive manner. These processes are preemptive of other adaptive cognitive processing and negatively affect the servicemember's ability to regulate arousal and engage in self-monitoring behaviors or other inhibitory processes.

Information processing models for anger and aggression highlight the role of additional factors that may affect the traumatized individual cognitively and further increase risk [12,40-41]. For example, depression, alcohol use problems, and traumatic brain injury (TBI) each often co-occur with PTSD and can have a negative effect on information processing, and each has been associated with the perpetration of aggression in previous research [47]. Although the literature has yet to fully examine the potentially complex interrelationships among these different risk factors and associations with aggression, it appears likely that the presence of more than one of these risk factors may increase risk in a multiplicative fashion (e.g., TBI disinhibits aggressive behavior among those with PTSD, depression, and/or alcohol use problems).

Researchers have identified several core themes that may underlie PTSD [48]. These themes may also contribute to anger and aggression and thus represent treatment targets. For example, trust in others is often disrupted following trauma, particularly if an individual thought to be trustworthy contributed to the trauma. Individuals with PTSD may feel that all people are out to hurt them and that they cannot trust anyone, which can lead to problems 
with anger and aggression. They may also experience profound shame and blame themselves for their traumas, which can lead to low self-esteem and conflict in relationships. PTSD-positive individuals may also have felt powerless during traumatic experiences, and feelings of powerlessness may contribute to power conflicts with others and controlling behavior following trauma exposure.

\section{Assessment of Anger and Aggression}

The VA/DOD clinical practice guideline recommends that clinicians assess "the nature of symptoms, severity and dangerousness," using standardized anger measures [1]. The guideline specifically recommends the use of the STAXI [17]. The more recent STAXI-2 is a revised version of the original instrument [49]. The STAXI-2 comprises 57 items that measure both the experience and expression of anger, and studies of the measure have supported adequate discriminant and convergent validity [50]. The psychometric properties of the measure have also been supported in military samples [17], and partner-violent men score higher than nonviolent men, indicating at least adequate discriminant validity [51].

The STAXI-2 comprises six scales, five subscales, and the Anger Expression Index (AX). The State Anger scale of the STAXI-2 measures the individual's present experience of anger, i.e. "How I feel right now." The Trait Anger of the STAXI-2 scale measures anger over time, i.e., "How I generally feel," and the AX specifically measure reactions and behaviors when angry. The AX provides a measure of anger expression, anger suppression, and control over the anger response.

Although the STAXI-2 offers clinicians a great deal of information about a patient's anger and behavioral responses to anger, it does not specifically measure incidents of aggression. One commonly used and wellvalidated measure of aggression is the Revised Conflict Tactics Scale (CTS2) [52]. The CTS2 is a 39-item selfreport measure in which respondents indicate how many times they and their intimate partner used various aggressive acts in a conflict over a period of time. The measure may also be adapted for people other than relationship partners. The CTS2 assesses for psychological, sexual, and physical aggression as well as injury and provides a measure of frequency and subscales addressing aggression severity. Other useful measures that are likely familiar to mental health providers and typically accessible at the VA include the Aggression scale of the Personality
Assessment Inventory [53] and the Anger scale of the Minnesota Multiphasic Personality Inventory-2 [54].

Elbogen et al. recently published an evidence-based guide for risk assessment with Veterans in which they describe a "look-adjust-examine" approach [21]. Briefly, the authors suggest that clinicians conceptualize risk for violence by first looking at individual-level static factors shown to be related to violent behavior in Veterans and follow up with an assessment of more dynamic factors, recognizing that a person's violence risk may fluctuate. In Veterans, four static factors have been associated with violence in four or more studies: younger age, past violent behavior, child maltreatment/abuse, and combat exposure. Elbogen et al. suggest that the risk assessment then be adjusted to account for more dynamic factors such as substance abuse, depression, and PTSD. Risk might be adjusted downward when patients are clinically stable and upward during symptom exacerbation, and thus clinicians may intervene with safety planning or increasing access to services. Additionally, treatment for underlying mental health issues may reduce risk for violence. Finally, Elbogen et al. suggest clinicians assess for other protective or harmful environmental factors such as financial stability or employment that may affect the Veteran's risk for violence [21]. As these factors may be modifiable, they represent another potential level of intervention at which clinicians can be helpful.

Higher rates of aggression have been reported in interview assessments as opposed to self-report intake forms [55], and specific clinical interview approaches may be useful for providers seeking to assess risk for aggression. Forgey et al. recently published the details of an evidence-based protocol for assessment of partner aggression in military populations, offering an outline of a standardized clinical interview and a checklist of risk factors that may be helpful for clinicians seeking guidance on key factors to cover in the clinical interview [56]. In addition to inquiring about areas such as history of relationship violence, legal involvement, family functioning (past and present), effect of deployment, and motivation for change, these authors emphasize that effective interviewing skills are particularly important when working with perpetrators or victims of violence.

In addition to reluctance to disclose, many clients who have perpetrated violence or are victims of violence experience significant guilt, shame, and distress. To combat this, clinicians will want to take a direct, specific, and nonjudgmental approach when asking clients about 
aggression and abuse perpetration and victimization [5758]. Clinicians may start with general questions such as, "What happens when you have a fight with your partner?" Clinicians should then follow up with specific questions like, "Has it ever gotten physical between the two of you during a fight?" It may also be important to ask questions that allow the client to respond affirmatively, i.e., "Have you ever hit your partner?” rather than "You don’t ever hit her, do you?” Motivational interviewing strategies may also be important in both conveying empathy and enhancing motivation for change [56].

Other helpful factors that may improve accuracy include making sure the interview is conducted in a private space, conducting ongoing assessment of violence issues because clients' willingness to disclose aggression may change over time, conducting collateral interviews to assess aggression and its effects more accurately, and thoroughly discussing the limits of confidentiality at the outset of treatment. Although reporting laws do not generally include mandated reporting for aggression toward other adults, clinicians should be aware of the specific duty to warn about provisions in their specific state and hospital. Finally, clinicians should be aware of referral options and hotline numbers, and they should be prepared to conduct a thorough safety assessment for any imminent danger.

\section{Effective Interventions for Anger and Aggression}

A number of interventions have been developed to assist individuals in managing their anger and aggression. These interventions have varied in content but have typically involved cognitive-behavioral techniques (e.g., challenging automatic anger-related thoughts and teaching relaxation skills, effective communication skills, and constructive coping strategies). Although research evaluating these interventions has not been as extensive compared with research examining treatments for anxiety and depression [59], studies have obtained support for the effectiveness of anger treatments in reducing anger and aggression among different populations, including community members, inmates, and inpatients [51,60-63].

Several meta-analyses have examined the overall effect that anger interventions have on anger and its various dimensions, including state and trait anger, anger control, anger expression, and aggressive behavior [59,64-66]. For example, DiGiuseppe and Tafrate examined 57 anger treatment studies and found that, overall, individuals who received anger treatment fared better than those who did not [59]. Furthermore, the average effect size $(d)$ for anger was 0.71 , while the average effect size $(d)$ for aggression was 1.16 , indicating moderate and large effects of anger interventions in improving anger symptoms and aggressive behavior, respectively. Del Vecchio and O'Leary also conducted a meta-analysis examining the effects of anger treatment on different aspects of anger [65]. They limited their review to studies that treated individuals who demonstrated clinically significant levels of anger and studies that used adult outpatients. These authors provided effect sizes based on the type of anger problem addressed and the type of treatment implemented (i.e., cognitive-behavioral, cognitive, relaxation training). Results showed that the average effect sizes $(d)$ ranged from 0.61 to 0.90 for the types of treatments examined, indicating a medium to large effect of these interventions in treating anger. Furthermore, they found that cognitive-behavioral therapy was most effective in treating problems related to anger expression (i.e., anger outbursts), while cognitive therapy was most effective in treating anger suppression problems (i.e., the tendency to hold anger in). Taken together, these findings provide support for the effectiveness of anger interventions in treating different anger problems and aggressive behavior, particularly those that use some form of behavioral, cognitive, or cognitive-behavioral interventions.

Anger management interventions have been implemented with Veterans with PTSD. Although very few studies have been conducted evaluating the effectiveness of such interventions, findings have shown positive results. For example, Gerlock implemented a cognitivebehavioral anger management intervention with 51 male Veterans [67]. Most of these Veterans (72\%) served in the Vietnam war, and about half (57\%) had diagnosable PTSD resulting from war trauma. Compared with their pretreatment scores, posttreatment scores indicated significant decreases in state and trait anger. This study provides support for the effectiveness of anger interventions for Veterans with PTSD; however, since no control group was implemented as part of the study, it is difficult to rule out alternative explanations that may account for the findings.

Chemtob et al. also implemented a cognitive-behavioral treatment for 15 Vietnam war combat Veterans with severe chronic PTSD and high anger [44]. Participants were randomly assigned to receive either anger treatment or routine clinical care. Results showed that, compared with those who received routine clinical care, individuals 
who participated in the anger treatment improved in their ability to control their anger, and these effects were maintained at the 18-month follow-up. These individuals also reported less intense reactions to anger-provoking situations.

Although these studies conducted by Chemtob et al. [44] and Gerlock [67] are promising in that they provide support for the effectiveness of anger interventions among Veterans with PTSD, they are limited in a number of respects. For example, as previously mentioned, the study conducted by Gerlock did not include a control group [67] and the Chemtob et al. study used a small sample [44]. Furthermore, neither study focused on aggression as an outcome, so it is unclear to what extent the interventions they implemented are effective in decreasing such behavior. Given the lack of rigorous research studies evaluating anger interventions with this population, additional research in this area is sorely needed. This research should involve the use of randomized controlled studies to evaluate anger management interventions and should include measures that assess both anger and aggression. Additional research should also focus on comparing different anger/aggression interventions and the extent to which treating PTSD will help reduce anger and aggression, in addition to trauma symptomatology.

Given the effectiveness of anger management interventions for Veterans with PTSD and co-occurring anger difficulties, researchers have begun to explore factors that may help predict differential treatment response, as well as different modalities for implementing such interventions. For example, Marshall et al. examined the effect of antisocial personality characteristics on the effectiveness of a cognitive-behavioral anger management group treatment [66]. Results showed pretreatment to posttreatment reduction in state and trait anger and physical aggression. As expected, antisocial personality traits were associated with smaller decreases in trait anger, anger expression, and physical aggression during treatment. In a study examining the effectiveness of a telemedicine modality, Morland et al. implemented a cognitive-behavioral group anger management treatment for Veterans with PTSD in which treatment was delivered with the therapist present or via video teleconferencing [68]. Both treatment groups demonstrated similar reductions in anger symptoms. Furthermore, the authors did not find any significant differences between the two groups on process variables including attrition, adherence, satisfaction, and treatment expectancy.
As these studies show, not only are anger management interventions effective in reducing problematic anger among Veterans with PTSD, but such interventions can be delivered in innovative ways to reach those who may not have immediate access to services. Furthermore, as more research in this area is conducted, we are in a better position to determine which individual characteristics could possibly impede treatment. Such information can aid in the refinement of anger interventions and assist in treatment-matching efforts.

\section{DISCUSSION}

In this section, we provide some tips for facilitating a positive therapeutic process and enhancing motivation in those who are attempting to work on anger issues. This population may exhibit a tendency to downplay difficulties with anger and aggression, and thus it is particularly important for providers not only to focus on the technical aspects of the interventions they employ but also to deal with process and motivational issues.

At the outset of therapy and throughout the therapy process, it is critical that the provider convey a sense of hopefulness. Many Veterans experiencing anger problems may enter treatment with the idea that it is not possible for them to learn new, more adaptive ways of dealing with their anger. Providers need to communicate hopefulness and optimism, at times explicitly, but more often implicitly, by reflecting on the Veteran's desire for things to change and by identifying his/her strengths and positive behaviors, as well as other aspects of their lives that they have managed to successfully improve.

When a Veteran discusses his or her use of a new anger management skill, it may be helpful for the provider to ask "How is this different than what you've done in the past?" to highlight the progress and the different outcomes that arise from using new skills. It is also helpful to always comment on the positive work the Veteran has done before exploring problem areas or assignments completed incorrectly. Although the provider never wants to "collude" with the Veteran's potentially aggressive behavior, it is often possible to empathize with some aspects of the situation and identify some positive features in how the Veteran has handled it. Another strategy to elicit motivational statements is to ask the Veteran how he or she might handle the situation differently if he or she could go back in time and relive the event. Typically, 
when this question is posed in reference to a situation in which the Veteran behaved aggressively, the Veteran will acknowledge that there may have been more appropriate and healthy ways of dealing with the situation.

For particularly unmotivated Veterans seeking anger management, it is important for providers to be direct when the client exhibits behaviors that indicate questionable investment in the intervention. Remind the Veteran that he or she is taking the time to come in for help, so he or she may as well put his or her best foot forward. Ask the Veteran if he or she can adopt a "let's wait and see" attitude throughout participation. If a Veteran expresses hesitance to try a new skill or does not see the benefit of working on anger, the provider may ask, "How is your current style working for you?” It may be helpful to examine the "pros" and "cons" of the Veteran's aggressive behavior. This typically involves assisting the Veteran to write down all of the positive and negative things that he or she gets from his or her aggression. Typically, the Veteran will only be able to identify a few short-lived "pros" of aggression, such as tension release, the communication of intense emotions, forced compliance with one's demands, and a sense of control. Veterans are often able to list numerous "cons" of aggression, on the other hand, such as loss of relationships, financial problems, incarceration or loss of military status, social and family stigma, feelings of guilt and shame, etc. After lists of pros and cons are generated, the provider then points out that there are many more pros than cons and discusses with the Veteran if there are more effective ways to meet the goals of the pros (e.g., "Are there more effective ways to reduce tension or express one's feelings?”).

Groups can be particularly helpful for working on anger because they allow individuals to see that they are not alone and provide a forum for discussing and sharing difficult feelings and situations. A group setting also allows Veterans to model positive interpersonal behaviors and to provide feedback on appropriate ways of handling difficult issues. Some common interpersonal behaviors observed in session that often reflect problems outside the group are the tendency to experience difficulties listening to others, trouble expressing feelings, misinterpretation of other's intentions, mistrust of others, attempts to avoid discussions when uncomfortable issues arise, interruptions, etc. All require clinicians to pay careful attention to interpersonal processes in the group. Groups can also be particularly powerful with this population because there will inevitably be group members who are further along in their change efforts, and these members can serve as role models for other group members and may also assist in providing useful feedback and encouragement. Leaders should be sure to identify, however, situations in which an individual is serving as consistent "expert" in the group in order to avoid working on his or her own problems. It is recommended that the reader refer to Yalom for further material on promoting a positive group process [69].

\section{CONCLUSIONS}

Problematic anger and aggression frequently occur with PTSD, and treatment of these problems is recommended in the 2010 VA/DOD Clinical Practice Guideline for Management of Post-Traumatic Stress. Research has shown that anger can interfere with PTSD treatment, and that anger and aggression are linked to PTSD and PTSD severity. Several other risk factors can increase risk for anger and aggression, and information processing models have been used to help explain the etiology of these problems in traumatized individuals. Clinicians should incorporate thorough assessment of anger and aggression into their practice, including the use of validated self-report measures combined with clinician interview, and these assessments should inform the anger interventions employed. It is also critically important for providers to be attuned to process and motivational considerations when working with this population.

\section{ACKNOWLEDGMENTS}

\section{Author Contributions:}

Drafting of manuscript: C. T. Taft, S. K. Creech, L. Kachadourian. Critical revision of manuscript for important intellectual content: C. T. Taft, S. K. Creech, L. Kachadourian.

Financial Disclosures: The authors have declared that no competing interests exist.

Funding/Support: This material was based on work supported by the National Institute of Mental Health (grant K08 MH7311701A2 to the first author and grant T32MH019836).

Disclaimer: The content is solely the responsibility of the authors and does not necessarily represent the official views of the National Institute of Mental Health or the National Institutes of Health. 


\section{REFERENCES}

1. Management of Post-Traumatic Stress Working Group [Internet]. VA/DOD clinical practice guideline for Management of post-traumatic stress. Washington (DC): Department of Veterans Affairs, Department of Defense; 2010. Available from: http://www.healthquality.va.gov/ptsd/ptsd_full.pdf

2. Ax AF. The physiological differentiation between fear and anger in humans. Psychosom Med. 1953;15(5):433-42. [PMID:13100546]

3. Spielberger CD, Jacobs G, Russell JS, Crane RS. Assessment of anger: the state-trait anger scale. In: Butcher JN, Spielberger CD, editors. Advances in personality assessment, vol 2. Hillside (NJ): Erlbaum; 1983.

4. Eckhardt C, Norlander B, Deffenbacher J. The assessment of anger and hostility: A critical review. Aggress Violent Behav. 2004;9:17-43.

http://dx.doi.org/10.1016/S1359-1789(02)00116-7

5. Eckhardt CI, Deffenbacher JL. Diagnosis of anger disorders. In: Kassinove $\mathrm{H}$, editor. Anger disorders: definition, diagnosis, and treatment. Washington (DC): Taylor \& Francis; 1995. p. 27-48.

6. Kassinove H, Sukhodolsky DG. (1995). Anger disorders: basic science and practice issues. In: Kassinove H, editor. Anger disorders: definition, diagnosis, and treatment. Washington (DC): Taylor \& Francis; 1995. p. 1-27.

7. Baron RA, Richardson DR. Human aggression, 2nd ed. New York (NY): Plenum Press; 1994.

8. Reilly PM, Shopshire MS. Anger management for substance abuse and mental health clients: A cognitive behavioral therapy manual. Rockville (MD): Center for Substance Abuse Treatment, Substance Abuse and Mental Health Services Administration; 2008. DHHS Pub. No. (SMA) 08-4213.

9. Buss AH, Perry M. The aggression questionnaire. J Pers Soc Psychol. 1992;63(3):452-59. [PMID:1403624] http://dx.doi.org/10.1037/0022-3514.63.3.452

10. Buss AH. The psychology of aggression. New York (NY): Wiley; 1961.

11. Berkowitz L. Towards a general theory of anger and emotional aggression: Implications of the cognitive-neoassociationistic perspective for the analysis of anger and other emotions. In: Wyer RS, Srull TK, editors. Perspectives on anger and emotion, vol 6. Hillsdale (NJ): Lawrence Erlbaum Associates; 1993. p. 1-46.

12. Chemtob CM, Hamada RS, Roitblat HL, Muraoka MY. Anger, impulsivity, and anger control in combat-related posttraumatic stress disorder. J Consult Clin Psychol. 1994;62(4):827-32. [PMID:7962887] http://dx.doi.org/10.1037/0022-006X.62.4.827

13. Frueh BC, Henning KR, Pellegrin KL, Chobot K. Relationship between scores on anger measures and PTSD symp- tomatology, employment, and compensation-seeking status in combat veterans. J Clin Psychol. 1997;53(8):871-78.

[PMID:9403390]

http://dx.doi.org/10.1002/(SICI)1097-

4679(199712)53:8<871::AID-JCLP12>3.0.CO;2-H

14. Riggs DS, Dancu CV, Gershuny BS, Greenberg D, Foa EB. Anger and post-traumatic stress disorder in female crime victims. J Trauma Stress. 1992;5(4):613-25.

http://dx.doi.org/10.1002/jts.2490050410

15. Schützwohl M, Maercker A. Anger in former East German political prisoners: relationship to posttraumatic stress reactions and social support. J Nerv Ment Dis. 2000; 188(8):483-89. [PMID:10972566]

http://dx.doi.org/10.1097/00005053-200008000-00002

16. Orth U, Wieland E. Anger, hostility, and posttraumatic stress disorder in trauma-exposed adults: a meta-analysis. J Consult Clin Psychol. 2006;74(4):698-706.

[PMID:16881777]

http://dx.doi.org/10.1037/0022-006X.74.4.698

17. Spielberger CD, Sydeman SJ, Owen AE, Marsh BJ. Measuring anxiety and anger with the State-Trait Anxiety Inventory (STAI) and the State-Trait Anger Expression Inventory (STAXI). In: Maruish ME, editor. The use of psychological testing for treatment planning and outcomes assessment. Mahwah (NJ): Erlbaum; 1999. p. 993-1021.

18. Olatunji BO, Ciesielski BG, Tolin DF. Fear and loathing: a meta-analytic review of the specificity of anger in PTSD. Behav Ther. 2010;41(1):93-105. [PMID:20171331] http://dx.doi.org/10.1016/j.beth.2009.01.004

19. Beckham JC, Feldman ME, Kirby AC, Hertzberg MA, Moore SD. Interpersonal violence and its correlates in Vietnam veterans with chronic posttraumatic stress disorder. J Clin Psychol. 1997;53(8):859-69. [PMID:9403389] http://dx.doi.org/10.1002/(SICI)10974679(199712)53:8<859::AID-JCLP11>3.0.CO;2-J

20. Castillo DT, Baca JC, Conforti K, Qualls C, Fallon SK. Anger in PTSD: General psychiatric and gender differences on the BDHI. J Loss Trauma. 2002;7(2):119-28. http://dx.doi.org/10.1080/153250202753472282

21. Elbogen EB, Fuller S, Johnson SC, Brooks S, Kinneer P, Calhoun PS, Beckham JC. Improving risk assessment of violence among military veterans: an evidence-based approach for clinical decision-making. Clin Psychol Rev. 2010;30(6):595-607. [PMID:20627387] http://dx.doi.org/10.1016/j.cpr.2010.03.009

22. Jakupcak M, Conybeare D, Phelps L, Hunt S, Holmes HA, Felker B, Klevens M, McFall ME. Anger, hostility, and aggression among Iraq and Afghanistan War veterans reporting PTSD and subthreshold PTSD. J Trauma Stress. 2007;20(6):945-54. [PMID:18157891] http://dx.doi.org/10.1002/jts.20258 
23. Novaco RW, Chemtob CM. Anger and combat-related posttraumatic stress disorder. J Trauma Stress. 2002;15(2): 123-32. [PMID:12013063] http://dx.doi.org/10.1023/A:1014855924072

24. Forbes D, Creamer M, Hawthorne G, Allen N, McHugh T. Comorbidity as a predictor of symptom change after treatment in combat-related posttraumatic stress disorder. J Nerv Ment Dis. 2003;191(2):93-99. [PMID:12586962] http://dx.doi.org/10.1097/01.NMD.0000051903.60517.98

25. Orth U, Cahill SP, Foa EB, Maercker A. Anger and posttraumatic stress disorder symptoms in crime victims: a longitudinal analysis. J Consult Clin Psychol. 2008;76(2): 208-18. [PMID:18377118]

http://dx.doi.org/10.1037/0022-006X.76.2.208

26. Forbes D, Parslow R, Creamer M, Allen N, McHugh T, Hopwood M. Mechanisms of anger and treatment outcome in combat veterans with posttraumatic stress disorder. J Trauma Stress. 2008;21(2):142-49. [PMID:18404639] http://dx.doi.org/10.1002/jts.20315

27. Biddle D, Elliott P, Creamer M, Forbes D, Devilly GJ. Selfreported problems: a comparison between PTSD-diagnosed veterans, their spouses, and clinicians. Behav Res Ther. 2002;40(7):853-65. [PMID:12074378] http://dx.doi.org/10.1016/S0005-7967(01)00084-5

28. Kivisto AJ, Moore TM, Elkins SR, Rhatigan DL. The effects of PTSD symptomatology on laboratory-based aggression. J Trauma Stress. 2009;22(4):344-47. [PMID:19588511] http://dx.doi.org/10.1002/jts.20425

29. Taft CT, Monson CM, Schumm JA, Watkins LE, Panuzio J, Resick PA. Posttraumatic stress disorder symptoms, relationship adjustment, and relationship aggression in a sample of female flood victims. J Fam Violence. 2009; 24(6):389-96. [PMID:21057584] http://dx.doi.org/10.1007/s10896-009-9241-8

30. Taft CT, Vogt DS, Marshall AD, Panuzio J, Niles BL. Aggression among combat veterans: relationships with combat exposure and symptoms of posttraumatic stress disorder, dysphoria, and anxiety. J Trauma Stress. 2007;20(2): 135-45. [PMID:17427912] http://dx.doi.org/10.1002/jts.20197

31. Taft CT, Weatherill RP, Woodward HE, Pinto LA, Watkins LE, Miller MW, Dekel R. Intimate partner and general aggression perpetration among combat veterans presenting to a posttraumatic stress disorder clinic. Am J Orthopsychiatry. 2009;79(4):461-68. [PMID:20099937]

http://dx.doi.org/10.1037/a0016657

32. Taft CT, Schumm J, Orazem RJ, Meis L, Pinto LA. Examining the link between posttraumatic stress disorder symptoms and dating aggression perpetration. Violence Vict. 2010;25(4):456-69. http://dx.doi.org/10.1891/0886-6708.25.4.456 [PMID:20712145]

33. Teten AL, Miller LA, Stanford MS, Petersen NJ, Bailey SD, Collins RL, Dunn NJ, Kent TA. Characterizing aggression and its association to anger and hostility among male veterans with post-traumatic stress disorder. Mil Med. 2010;175(6):405-10. [PMID:20572472]

34. Kulka R, Schlenger W, Fairbank J, Hough R, Jordan B, Marmar C, Weiss DS. The National Vietnam Veterans Readjustment Study: Tables of findings and technical appendices. New York: Brunner/Mazel; 1990.

35. Jordan BK, Marmar CR, Fairbank JA, Schlenger WE, Kulka RA, Hough RL, Weiss DS. Problems in families of male Vietnam veterans with posttraumatic stress disorder. J Consult Clin Psychol. 1992;60(6):916-26.

[PMID:1460153] http://dx.doi.org/10.1037/0022-006X.60.6.916

36. Orcutt HK, King LA, King DW. Male-perpetrated violence among Vietnam veteran couples: relationships with veteran's early life characteristics, trauma history, and PTSD symptomatology. J Trauma Stress. 2003;16(4):381-90. [PMID:12895021] http://dx.doi.org/10.1023/A:1024470103325

37. Riggs DS, Byrne CA, Weathers FW, Litz BT. The quality of the intimate relationships of male Vietnam veterans: problems associated with posttraumatic stress disorder. J Trauma Stress. 1998;11(1):87-101. [PMID:9479678] http://dx.doi.org/10.1023/A:1024409200155

38. Sherman MD, Sautter F, Jackson MH, Lyons JA, Han X. Domestic violence in veterans with posttraumatic stress disorder who seek couples therapy. J Marital Fam Ther. 2006;32(4):479-90. [PMID:17120520] http://dx.doi.org/10.1111/j.1752-0606.2006.tb01622.x

39. Savarese VW, Suvak MK, King LA, King DW. Relationships among alcohol use, hyperarousal, and marital abuse and violence in Vietnam veterans. J Trauma Stress. 2001; 14(4):717-32. [PMID:11776419] http://dx.doi.org/10.1023/A:1013038021175

40. Taft CT, Walling SM, Howard JM, Monson C. Trauma, PTSD, and partner violence in military families. In: MacDermid Wadsworth S, Riggs D, editors. Risk and resilience in U.S. military families. New York (NY): Springer; 2011. p. 195-212.

41. Holtzworth-Munroe A. Social skills deficits in maritally violent men: Interpreting the data using a social information processing model. Clin Psychol Rev. 1992;12:605-17. http://dx.doi.org/10.1016/0272-7358(92)90134-T

42. Eckhardt CI, Barbour KA, Davison GC. Articulated thoughts of maritally violent and nonviolent men during anger arousal. J Consult Clin Psychol. 1998;66(2):259-69. [PMID:9583329] http://dx.doi.org/10.1037/0022-006X.66.2.259 
43. Constans J. Information processing biases in PTSD. In: Vasterling JJ, Brewin CR, editors. Neuropsychology of PTSD: biological, cognitive, and clinical perspectives. New York (NY): The Guilford Press; 2005. p. 105-30.

44. Chemtob CM, Novaco RW, Hamada RS, Gross DM. Cognitive-behavioral treatment for severe anger in posttraumatic stress disorder. J Consult Clin Psychol. 1997;65(1): 184-89. [PMID:9103748] http://dx.doi.org/10.1037/0022-006X.65.1.184

45. Chemtob CM, Novaco RW, Hamada RS, Gross DM, Smith G. Anger regulation deficits in combat-related posttraumatic stress disorder. J Trauma Stress. 1997;10(1):17-36. [PMID:9018675] http://dx.doi.org/10.1002/jts.2490100104

46. Novaco RW, Chemtob CM. Anger and trauma: Conceptualization, assessment, and treatment. In: Follette VM, Ruzek JI, Abueg FR, editors. Cognitive-behavioral therapies for trauma. New York (NY): Guilford Press; 1998. p. 162-90.

47. Heyman RE, Taft C, Collins P, Howard JM, Macdonald A. Couple-based approaches to intimate partner violence. In: Snyder DK, Monson CM, editors. Couple-based interventions for military and veteran families: promoting individual and relationship well-being. New York (NY): Guilford; 2012.

48. Resick PA, Schnicke MK. Cognitive processing therapy for sexual assault victims. J Consult Clin Psychol. 1992;60(5): 748-56. [PMID:1401390] http://dx.doi.org/10.1037/0022-006X.60.5.748

49. Speilberger C. STAXI-2: The State Trait Anger Expression Inventory-2: professional manual. Odessa (FL): Psychological Assessment Resources; 1999.

50. Deffenbacher JL, Oetting ER, Thwaites GA, Lynch RS, Baker DA, Stark RS, Thacker S, Eiswerth-Cox L. Statetrait anger theory and the utility of the trait anger scale. J Consult Psychol. 1996;43(2):131-48.

51. Barbour KA, Eckhardt CI, Davison GC, Kassinove H. The experience and expression of anger in maritally violent and maritally discordant-nonviolent men. Behav Ther. 1998; 29(2):173-91. http://dx.doi.org/10.1016/S0005-7894(98)80001-4

52. Straus MA, Hamby SL, Boney-McCoy S, Sugarman DB. The Revised Conflict Tactics Scales (CTS2): Development and preliminary psychometric data. J Fam Issues. 1996; 17(3):283-316. http://dx.doi.org/10.1177/019251396017003001

53. Morey LC. Personality assessment inventory (PAI): professional manual. Odessa (TX): Psychological Assessment Resources; 1991.

54. Butcher JN, Graham J, Williams C, Ben-Porath Y. Development and use of the MMPI-2 content scales. Minneapolis (MN): University of Minnesota Press; 1990.
55. McFarlane J, Christoffel K, Bateman L, Miller V, Bullock L. Assessing for abuse: self-report versus nurse interview. Public Health Nurs. 1991;8(4):245-50. [PMID:1766908] http://dx.doi.org/10.1111/j.1525-1446.1991.tb00664.x

56. Forgey MA, Badger L, Krase K. The development of an evidence based assessment protocol for intimate partner violence in the U.S. Army. J Evid Based Soc Work. 2011; 8(3):323-48. [PMID:21660826] http://dx.doi.org/10.1080/15433714.2011.533946

57. Bonomi AE, Allen DG, Holt VL. Conversational silence, coercion, equality: the role of language in influencing who gets identified as abused. Soc Sci Med. 2006;62(9):2258-66. [PMID:16289736] http://dx.doi.org/10.1016/j.socscimed.2005.10.022

58. Riggs DS, Caulfield MB, Street AE. Risk for domestic violence: factors associated with perpetration and victimization. J Clin Psychol. 2000;56(10):1289-1316. [PMID:16289736] http://dx.doi.org/10.1002/10974679(200010)56:10<1289::AID-JCLP4>3.0.CO;2-Z

59. DiGiuseppe R, Tafrate RC. Anger treatment for adults: A meta-analytic review. Clin Psychol Sci Pract. 2003;10(1): 70-84. http://dx.doi.org/10.1093/clipsy.10.1.70

60. Forbes MR, Pratsinak GJ, Fagan TJ, Ax RK. Effects of group prosocial skills training on anger control in prison inmates. Psychol Rep. 1992;70(1):66. [PMID:1565747] http://dx.doi.org/10.2466/pr0.1992.70.1.66

61. Stermac LE. Anger control treatment for forensic patients. J Interpers Violence. 1986;1(4):446-57. http://dx.doi.org/10.1177/088626086001004004

62. Tafrate RC, Kassinove H. Anger control in men: Barb exposure with rational, irrational, and irrelevant self-statements. J Cogn Psychother. 1998;12(3):187-211.

63. Beck R, Fernandez E. Cognitive behavioral therapy in the treatment of anger: A meta-analysis. Cognit Ther Res. 1998;22(1):63-74. http://dx.doi.org/10.1023/A:1018763902991

64. Bowman Edmondson C, Cohen Conger J. A review of treatment efficacy for individuals with anger problems: Conceptual, assessment and methodological issues. Clin Psychol Rev. 1996;16(3):251-75. http://dx.doi.org/10.1016/S0272-7358(96)90003-3

65. Del Vecchio T, O’Leary KD. Effectiveness of anger treatments for specific anger problems: a meta-analytic review. Clin Psychol Rev. 2004;24(1):15-34. [PMID:14992805] http://dx.doi.org/10.1016/j.cpr.2003.09.006

66. Marshall AD, Martin EK, Warfield GA, Doron-Lamarca S, Niles BL, Taft CT. The impact of antisocial personality characteristics on anger management treatment for veterans with PTSD. Psychol Trauma. 2010;2(3):224-31. http://dx.doi.org/10.1037/a0019890

67. Gerlock AA. Veterans' responses to anger management intervention. Issues Ment Health Nurs. 1994;15(4):393-408. 
JRRD, Volume 49, Number 5, 2012

\section{[PMID:8056569]}

http://dx.doi.org/10.3109/01612849409006916

68. Morland LA, Greene CJ, Rosen CS, Foy D, Reilly P, Shore J, He Q, Frueh BC. Telemedicine for anger management therapy in a rural population of combat veterans with posttraumatic stress disorder: a randomized noninferiority trial. J Clin Psychiatry. 2010;71(7):855-63. [PMID:20122374] http://dx.doi.org/10.4088/JCP.09m05604blu

69. Yalom ID. The theory and practice of group psychotherapy, 4th ed. New York (NY): Basic Books; 1995.

Submitted for publication September 2, 2011. Accepted in revised form January 3, 2012.
This article and any supplementary material should be cited as follows:

Taft CT, Creech SK, Kachadourian L. Assessment and treatment of posttraumatic anger and aggression: A review. J Rehabil Res Dev. 2012;49(5):777-88.

http://dx.doi.org/10.1682/JRRD.2011.09.0156

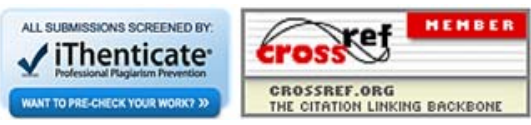

